\title{
Association of mid-infrared-predicted milk and blood constituents with early-lactation disease, removal, and production outcomes in Holstein cows
}

\author{
K. D. Bach, ${ }^{1}$ D. M. Barbano, ${ }^{2}$ and J. A. A. McArt ${ }^{1 *}$ \\ ${ }^{1}$ Department of Population Medicine and Diagnostic Sciences, College of Veterinary Medicine, Cornell University, Ithaca, NY 14853 \\ ${ }^{2}$ Department of Food Science, College of Agriculture and Life Sciences, Cornell University, Ithaca, NY 14853
}

\begin{abstract}
Partial least squares regression estimates of milk and blood constituents using Fourier-transform midinfrared (FTIR) analysis have shown promise as a tool for monitoring early-lactation excessive energy deficit in dairy herds. Our objective was to analyze milk via FTIR to determine the association of early-lactation predicted milk $\beta$-hydroxybutyrate (BHB) concentrations, predicted blood nonesterified fatty acid (NEFA) concentrations, and predicted milk de novo fatty acid (FA) percentages relative to total FA concentrations, with the risk of disease or removal in early lactation (hyperketonemia, displaced abomasum, metritis, culling, or death) and average daily milk yield during the first 15 wk of lactation. We enrolled 517 multiparous Holstein cows from 2 dairy farms in New York. Composite milk samples were collected twice weekly from 3 to 18 DIM for a total of 4 timepoints (T1, T2, T3, T4) and analyzed using FTIR spectrometry for milk BHB and FA composition and predicted blood NEFA. Blood samples were collected for hyperketonemia determination (BHB $\geq 1.2 \mathrm{mmol} / \mathrm{L})$ using a handheld meter, and farm-diagnosed occurrence of disease or removal during the first 30 DIM and average daily milk yield during the first 15 wk of lactation were collected from herd management software. The incidence of disease or removal between 3 and 18 DIM was $20.2 \%$. Explanatory models for disease or removal were developed for each predicted constituent of interest at each timepoint using fixed-effect multivariable Poisson regression. Repeated measures ANOVA models were developed for each predicted constituent to assess differences in average daily milk yield. For all timepoints, increased risk of disease or removal was associated with higher predicted milk BHB [relative risk $(\mathrm{RR})_{\mathrm{T} 1}=2.0 ; \mathrm{RR}_{\mathrm{T} 2}$ $\left.=3.4 ; \mathrm{RR}_{\mathrm{T} 3}=5.2 ; \mathrm{RR}_{\mathrm{T} 4}=9.1\right]$, higher predicted blood
\end{abstract}

Received May 7, 2019.

Accepted July 9, 2019.

*Corresponding author: jmcart@cornell.edu
NEFA $\left(\mathrm{RR}_{\mathrm{T} 1}=2.7 ; \mathrm{RR}_{\mathrm{T} 2}=2.5 ; \mathrm{RR}_{\mathrm{T} 3}=3.8 ; \mathrm{RR}_{\mathrm{T} 4}=\right.$ 10.0), and lower predicted milk de novo $\mathrm{FA}$ relative percentages $\left(\mathrm{RR}_{\mathrm{T} 1}=2.9 ; \mathrm{RR}_{\mathrm{T} 2}=3.3 ; \mathrm{RR}_{\mathrm{T} 3}=5.8\right.$; $\mathrm{RR}_{\mathrm{T} 4}=7.2$ ). Average daily milk yield was increased for cows above the cut point for predicted milk BHB (2.1 $\mathrm{kg} / \mathrm{d})$ and predicted blood NEFA $(3.5 \mathrm{~kg} / \mathrm{d})$ and below the cut point for de novo FA relative percentages $(2.3$ $\mathrm{kg} / \mathrm{d}$ ). Our results suggest that FTIR-predicted milk BHB, blood NEFA, and milk de novo FA relative percentages are promising indicators of subsequent disease or removal in early lactation; their positive relationship with milk yield warrants further exploration.

Key words: milk, $\beta$-hydroxybutyrate, mid-FTIR

\section{INTRODUCTION}

As cows transition from late gestation to early lactation, they visit a state of energy deficit due to increased energy demands of lactation coupled with decreases in DM intake (Bauman and Currie, 1980; Baird, 1982; Herdt, 2000). In response to this deficit, fat stores are broken down, releasing nonesterified fatty acids (NEFA) which, among other possibilities, lead to production of ketone bodies such as BHB (Palmquist et al., 1969; Herdt, 2000). Although production of NEFA and $\mathrm{BHB}$ is a normal adaptation during this period of energy deficit, excessive blood concentrations of these metabolites have been associated with increased risk of detrimental health and production outcomes (Ospina et al., 2010; Chapinal et al., 2011; McArt et al., 2012a).

In early lactation, the incidence of elevated blood BHB, or hyperketonemia (HYK), in herds averages 40 to $60 \%$, making it a widespread issue in the dairy industry (Duffield et al., 1998; McArt et al., 2012b). With over $85 \%$ of cows with HYK showing no clinical signs of disease (Duffield et al., 2009), monitoring animals using handheld BHB meters has become the mainstay for disease detection. Although very effective (Iwersen et al., 2009; Bach et al., 2016), this method is laborious and costly. Fortunately, with the development of partial least squares (PLS) regression estimates of 
milk and blood constituents using Fourier-transform mid-infrared (FTIR) analysis of milk, a viable alternative for monitoring early lactation excessive energy deficit in dairy herds could become available.

Multiple studies have examined mid-FTIR methods for diagnosis of HYK using milk estimated BHB, acetone, as well as milk fat-to-protein ratios (Duffield et al., 1997; Denis-Robichaud et al., 2014; Santschi et al., 2016). Most of these studies have used DHIA monthly test-day milk samples (de Roos et al., 2007; DenisRobichaud et al., 2014; Santschi et al., 2016) and have established this technology as a good herd monitoring tool, especially in combination with additional testday and herd information (van der Drift et al., 2012; Chandler et al., 2018; Pralle et al., 2018). However, the single monthly sample limits detection at the cow level and decreases the capacity to examine individual risk. Additionally, these studies have not fully examined the association of predicted milk BHB with health or production outcomes.

More recently, additional milk predicted constituents have been explored, including estimated blood NEFA and predicted de novo fatty acid (FA) percentages relative to total FA concentrations (Woolpert et al., 2016; Luke et al., 2019). These predicted constituents have shown promise for individual cow HYK monitoring, as alterations in these constituents have been linked to development of clinical ketosis and displaced abomasum (DA; Pape et al., 2018). However, the associations of these various predicted constituents with subsequent disease events, herd removal, and production outcomes have yet to be fully established.

Therefore, our objectives were to determine the association of early lactation predicted milk BHB concentrations, predicted blood NEFA concentrations, and predicted de novo FA percentages relative to total FA concentrations with the risk of disease or removal (HYK, DA, metritis, culling, or death) and early-lactation milk yield.

\section{MATERIALS AND METHODS}

\section{Study Population}

Data were collected from 2 dairy farms (farms A and B) in New York from July through November 2016. To be selected, farms had to meet the following criteria: milk at least 1,000 cows, have headlocks in fresh cow pens, use the farm management program DairyComp 305 (Valley Agricultural Software, Tulare, CA), and be willing to participate in the proposed testing protocol. Farm A milked 1,060 cows 3 times daily and averaged $43 \mathrm{~kg} / \mathrm{d}$ of milk per cow during the study period. Farm B milked 1,100 cows 3 times daily and averaged $41 \mathrm{~kg} / \mathrm{d}$ of milk per cow during the study period. Both herds housed cows in freestall barns with concrete floors and fed a TMR. Farm A bedded with sand, whereas farm B used mattresses and recycled paper pulp.

\section{Data Collection and Study Design}

Enrollment for our prospective cohort study began at calving, and all multiparous cows were eligible for enrollment. Samples were collected from 3 to 18 DIM and occurred twice weekly for each farm: for farm A on Mondays and Thursdays, and for farm B on Tuesdays and Fridays. Given this testing scheme, each cow was sampled 4 times. Timepoints were as follows: 3 to 7 DIM (T1), 6 to 11 DIM (T2), 10 to 14 DIM (T3), and 13 to 18 DIM (T4). During each sampling day, a composite milk sample and whole-blood sample were collected. All milk samples were collected during the morning milking. Blood samples were collected during fresh cow lockup, which was immediately before milking for farm A and immediately following milking for farm B. All blood samples were taken within $1 \mathrm{~h}$ of milking.

For milk sampling, animals were identified by automatic, parlor radio-frequency identification detection and verified by visual animal tag identification. Milk samples were collected using International Committee on Animal Recordings-approved proportional milk samplers that were validated by our research team within 1 mo of milk sampling. Immediately following collection, $60-\mathrm{mL}$ aliquots were submerged in crushed ice until submission to the Department of Food Science at Cornell University (Ithaca, NY) for milk composition analysis.

For blood sampling, heparinized whole-blood samples were collected from a coccygeal vessel using $10-\mathrm{mL}$ heparinized evacuated tubes and 20-gauge, 2.54-cm blood collection needles. Blood samples were kept at room temperature until testing for HYK using a Nova Vet Meter (Nova Biomedical, Waltham, MA), which occurred within $4 \mathrm{~h}$ of collection (Iwersen et al., 2013; Megahed et al., 2017). Before testing, each blood sample was inverted gently 5 times; samples were evaluated following manufacturer guidelines. Samples with a BHB concentration $\geq 1.2 \mathrm{mmol} / \mathrm{L}$ were considered HYK positive.

Calving, health, and production data were extracted from DairyComp 305 on a weekly basis. Disease event data were recorded by on-farm personnel using standard disease definition protocols discussed before commencement of the trial. Metritis was defined as a fetid, reddish to brownish uterine discharge accompanied by systemic signs of illness (rectal temperature $\geq 39.5^{\circ} \mathrm{C}$ ). Displaced abomasum was defined as a classical resonant 
sound during simultaneous auscultation and percussion in a line from the tuber coxae to the olecranon, commonly referred to as a "ping." All DA diagnosed were left-sided. Body condition score (Ferguson et al., 1994) and locomotion score (LS; Sprecher et al., 1997), both on a 5-point scale, were performed by the first author on the first sampling day for each animal (3 to 7 DIM). Daily milk weights were averaged on a weekly basis to estimate average daily milk yield during the first $15 \mathrm{wk}$ of lactation.

Cows were excluded from the study if their previous days carried calf was less than $260 \mathrm{~d}(\mathrm{n}=14)$, if they were treated for clinical hypocalcemia $(n=1)$, or if they were prophylactically treated with propylene glycol by on-farm personnel ( $\mathrm{n}=45$; farm $\mathrm{A}$ only).

Approval for all animal procedures was granted by the Cornell University Institutional Animal Care and Use Committee (protocol 2015-0123). All farms were asked to sign a consent form agreeing to the proposed testing protocol.

\section{Milk Composition Analysis}

Milk fat, true protein, and anhydrous lactose content were determined using a FTIR spectrophotometer (Lactoscope model FTA, Delta Instruments, Drachten, the Netherlands) at the Department of Food Science at Cornell University (Ithaca, NY). The prediction models used were the optimized basic model filter wavelengths and intercorrection factors described by Kaylegian et al. (2009). Calibration of the FTIR for measurement of fat, true protein, and anhydrous lactose was performed using a 14-sample modified milk calibration set (Kaylegian et al., 2006) produced monthly. The reference chemistry values were an all-laboratory mean produced by a network of 10 to 12 laboratories running all samples with the reference methods (Wojciechowski et al., 2016). The reference methods for fat, true protein, and anhydrous lactose measurement were determined in duplicate in each laboratory, using the following validated methods (AOAC International, 2000): fat by modified Mojonnier ether extraction (method 989.05), true protein by Kjeldahl analysis (method 991.22), lactose by enzymatic analysis (method 2006.06), and total solids by atmospheric forced-air oven drying (method 990.20). Milk SCC was measured using a fluorometric flow cytometry method using DAPI $\left(4^{\prime}, 6\right.$-diamidino2-phenylindole) as the staining dye (SomaSmart, Delta Instruments). Calibration of the milk somatic cell counter was performed using calibration samples from the USDA Federal Milk Markets, with reference values established using the direct microscopic SCC method (Fitts and Laird, 2004).
De novo, mixed-origin, and preformed milk FA were measured directly as grams per $100 \mathrm{~g}$ of milk by FTIR using the PLS prediction models described by Woolpert et al. (2016). De novo FA relative percentages were determined by calculating the proportion of de novo FA (g/100 g of milk) compared with total milk FA (sum of de novo, mixed-origin, and preformed FA; $\mathrm{g} / 100 \mathrm{~g}$ of milk). Gas-liquid chromatography reference chemistry for calibration of the milk FA parameters was as described by Wojciechowski and Barbano (2016). The milk FA calibration sample set was the same 14-sample set that was used for calibration of the main milk components. The calibration concentration ranges for de novo, mixed-origin and preformed milk FA were as follows: de novo 0.05 to $1.4 \mathrm{~g} / 100 \mathrm{~g}$ milk; mixed-origin 0.08 to $2.2 \mathrm{~g} / 100 \mathrm{~g}$ milk; and preformed 0.06 to $1.9 \mathrm{~g} / 100 \mathrm{~g}$ milk. Milk urea nitrogen was measured by FTIR using a PLS model developed by Delta Instruments (parameter number 502) and calibrated using reference chemistry values from an enzymatic milk urea nitrogen assay (Megazyme, kit K-URAMR, Bray, Wicklow, Ireland). Milk estimated blood NEFA and milk BHB were also measured by FTIR using a PLS model developed by Delta Instruments (parameter numbers 1603 and 1601, respectively).

\section{Statistical Analysis}

All statistical analyses were performed in SAS version 9.4 (SAS Institute Inc., Cary, NC). Graphs were created using Microsoft Excel (2018; Microsoft Corp., Redmond, WA). Descriptive statistics were performed using PROC FREQ and PROC TTEST. Correlation between variables was determined using PROC CORR, with variables considered to be associated if their correlation coefficient was greater than or equal to 0.3 ; no variables met this criterion. Correction for multiplecomparison was performed using a Bonferroni correction.

Explanatory models were developed to assess the association of disease or removal for each predicted constituent (milk BHB, predicted blood NEFA, and de novo FA) using fixed-effect multivariable Poisson regression with PROC GENMOD (Ospina et al., 2012) at each of the 4 timepoints (T1-4). Cows were categorized as having a disease or removal event during a particular timepoint if one or more of the following occurred on or after the day of sampling and within the first 30 DIM: the cow was sold, died, or was diagnosed with metritis, DA, or HYK. Additional potential variables used for analysis were herd, parity (2nd, $3 \mathrm{rd}$, or $\geq 4$ th lactation), BCS ( $<3$ or $\geq 3)$, LS ( $\leq 2$ or $>2$ ), and calving ease score, which was dichotomized for animals delivering 
live singletons with little or no aid during parturition and those with dystocias, twins, or stillbirths.

Potential risk factors were explored for their univariate association with the outcome of interest, using a chi-squared test. Variables with $P<0.20$ were offered to the multivariable model, and backward stepwise elimination using a $P>0.05$ was used for main effects variable selection. To account for the differences in disease incidences between the 2 farms, herd was forced into all models. Biologically important pairwise interactions with the milk constituent of interest were then explored with all remaining variables and removed via backward stepwise elimination using a $P>0.05$ only if at least $10 \%$ of cows were within each level of the contingency table between both variables in the pairwise interaction. Each milk constituent was first handled in the continuous scale throughout the model-building process and then dichotomized based on receiver operating characteristic (ROC) curves if the constituent remained important at $P \leq 0.05$. Dichotomization was performed to determine an optimized concentration cut point for each constituent at each time point, to aid in ease of interpretation and for on-farm relevance. Optimal cut points were calculated, weighing false-positive and false-negative results equally.

A single repeated measures model was developed for each predicted constituent using PROC MIXED with unstructured covariance for average daily milk yield during the first 15 wk of lactation. Cows that contributed milk samples at 2 or fewer time points were excluded from analysis $(\mathrm{n}=19)$ unless they were censored due to a died or sold event. Cut points for each milk predicted constituent were calculated by averaging the optimized cut points from each of the 4 timepoints based on their association with occurrence of disease or removal (milk BHB: $0.14 \pm 0.01 \mathrm{mmol} / \mathrm{L}$; predicted blood NEFA: $0.55 \pm 0.05 \mathrm{mmol} / \mathrm{L}$; de novo FA: $21.2 \pm$ $0.5 \mathrm{rel} \%$ ). Cows were classified as either above or below the cut point if they crossed that cut point at any time during the first 18 DIM. Additional potential variables used for analysis included disease or removal event (HYK, DA, metritis, culling, or death), herd, parity, BCS, LS, and calving ease score. Independent variables and their respective interaction terms were considered statistically significant if $P \leq 0.05$.

\section{RESULTS}

\section{Descriptive Statistics}

In total, we enrolled 517 cows, with 457 eligible for analysis. The incidence of disease or removal in cows repeatedly tested from 3 to 18 DIM was $20.2 \%$, with an incidence of HYK of $13.2 \%$, DA of $0.2 \%$, metritis of $5.9 \%$, and culling within the first 30 DIM of $3.1 \%$. Median blood BHB concentration was as follows: $\mathrm{T} 1=0.6$ $\mathrm{mmol} / \mathrm{L}$ (range: 0.2 to $2.0 \mathrm{mmol} / \mathrm{L}$ ), T2 $=0.6 \mathrm{mmol} / \mathrm{L}$ (range: 0.3 to $3.2 \mathrm{mmol} / \mathrm{L}$ ), T3 $=0.6 \mathrm{mmol} / \mathrm{L}$ (range: 0.3 to $2.7 \mathrm{mmol} / \mathrm{L}$ ), $\mathrm{T} 4=0.6 \mathrm{mmol} / \mathrm{L}$ (range: 0.2 to 2.5 $\mathrm{mmol} / \mathrm{L}$ ). Average milk fat at each time point was as follows: $\mathrm{T} 1=4.9 \%, \mathrm{~T} 2=4.6 \%, \mathrm{~T} 3=4.3 \%$, and $\mathrm{T} 4=$ $4.1 \%$. Average true protein was $\mathrm{T} 1=4.0 \%, \mathrm{~T} 2=3.6 \%$, $\mathrm{T} 3=3.3 \%, \mathrm{~T} 4=3.1 \%$. Average lactose was $\mathrm{T} 1=$ $4.2 \%, \mathrm{~T} 2=4.4 \%, \mathrm{~T} 3=4.5 \%, \mathrm{~T} 4=4.6 \%$. Descriptive statistics for the explanatory disease or removal model for each time point are provided in Table 1. Histograms showing the distribution of FTIR-predicted milk BHB, predicted blood NEFA, and relative percentages of de novo FA are shown in Figure 1. Descriptive statistics for constituents at each time point are displayed in Figure 2.

\section{Risk of Disease or Removal in Early Lactation}

All predicted constituents (milk BHB, predicted blood NEFA, and de novo FA) at all timepoints (T1-4) were associated with increased risk of disease or removal (Table 2). The risk of disease or removal increased as timepoint increased. Optimized cut points based on the association of predicted constituents with risk of disease or removal for each timepoint, their respective area under the curve, sensitivity, and specificity are presented in Table 2.

\section{Milk Production During the First 15 Wk of Lactation}

Average daily milk yield during the first 15 wk of lactation for cows above and below cut points for each predicted constituent (milk BHB, predicted blood NEFA, and de novo FA) are shown in Figure 3. The interaction of constituent and week of lactation was important for predicted blood NEFA $(P<0.001)$ and demonstrated a tendency for milk BHB $(P=0.06)$ and de novo FA $(P$ $=0.07$ ). The difference in average daily milk yield for cows above compared with below the cut point for milk BHB and predicted blood NEFA were $2.1 \mathrm{~kg} / \mathrm{d}$ and 3.5 $\mathrm{kg} / \mathrm{d}$, respectively. The difference in average daily milk yield for cows below as compared with above the cut point for de novo FA was $2.3 \mathrm{~kg} / \mathrm{d}$. Additional variables retained in all models included parity (all $P<0.01$ ) and LS (all $P<0.005$ ). The interaction of farm and week of lactation was retained in the milk BHB model $(P<0.001)$, and farm was retained in the predicted blood NEFA model $(P=0.005)$. 


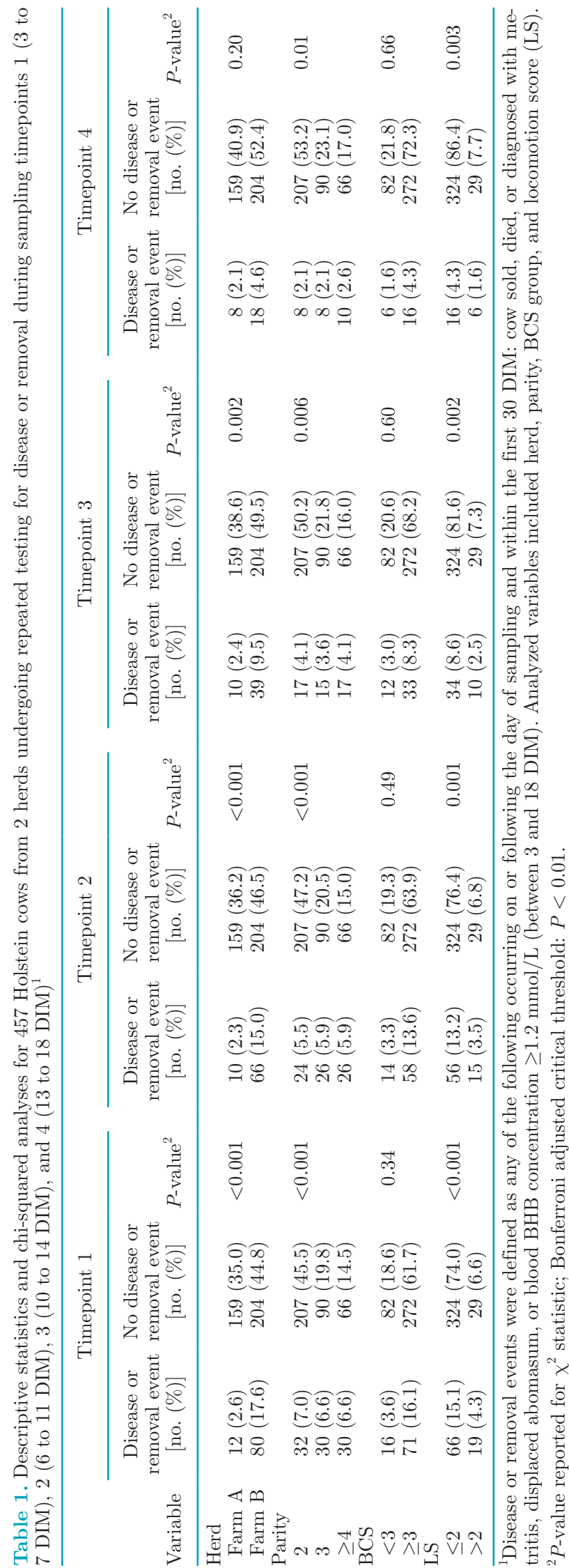

\section{DISCUSSION}

For our study, we hypothesized that cows experiencing disease or removal events during the first 30 DIM have increased milk BHB, as previously seen in studies looking at HYK as the lone outcome (van der Drift et al., 2012; Santschi et al., 2016; Chandler et al., 2018). We suspected the same for increases in predicted blood NEFA, as studies examining blood NEFA have demonstrated increased risk of negative health and production outcomes with elevated concentrations (Ospina et al., 2010; Chapinal et al., 2011, 2012). Additionally, we hypothesized that de novo FA concentrations would decrease in cows with disease or removal events, as previous work has shown decreases in de novo FA synthesis in cows undergoing excessive early lactation energy deficit (van Knegsel et al., 2005). All measured constituents (milk BHB, predicted blood NEFA, and de novo FA) behaved as expected, with increased concentrations of milk BHB and predicted blood NEFA and decreased concentrations of de novo FA noted at all timepoints for cows experiencing subsequent disease or removal events (Figure 2; $P<0.004$ for all except milk BHB at T4: $P=0.2$ ).

As can be seen in Table 2, the areas under the curve for most cut points determined by ROC analysis were greater than or equal to 0.70 , indicating useful discrimination ability according to Swets (1988). The T1 cut point for milk BHB and the T1, T2, and T3 cut points for de novo FA were very close to 0.70 , still indicating fair accuracy of these optimized cut points.

For milk BHB, cut points determined for each timepoint ranged from 0.11 to $0.17 \mathrm{mmol} / \mathrm{L}$ (Table 2). These findings were similar to other published reports, as were the associated sensitivity and specificity values (Tatone et al., 2017; Chandler et al., 2018; Renaud et al., 2019). When looking at these cut points over time, the optimal cut point concentration increased as the lactation proceeded. This is interesting when interpreted with the data from Figures 1 and 2, suggesting that the peak in milk BHB does not occur at 5 DIM, as seen in blood (McArt et al., 2012a), but potentially later. This notion has also been demonstrated previously by de Roos et al. (2007), who suggested that milk BHB may not peak until 3 wk in milk, and by Santschi et al. (2016), who reported peak prevalence of elevated milk BHB in multiparous cows during the second week in milk.

These findings suggest a potential limitation in our study design as well as with predicted milk BHB. Because screening for excessive energy deficit using blood NEFA or BHB is best performed from 3 to 14 DIM (Ospina et al., 2010), we chose a sampling window of 3 


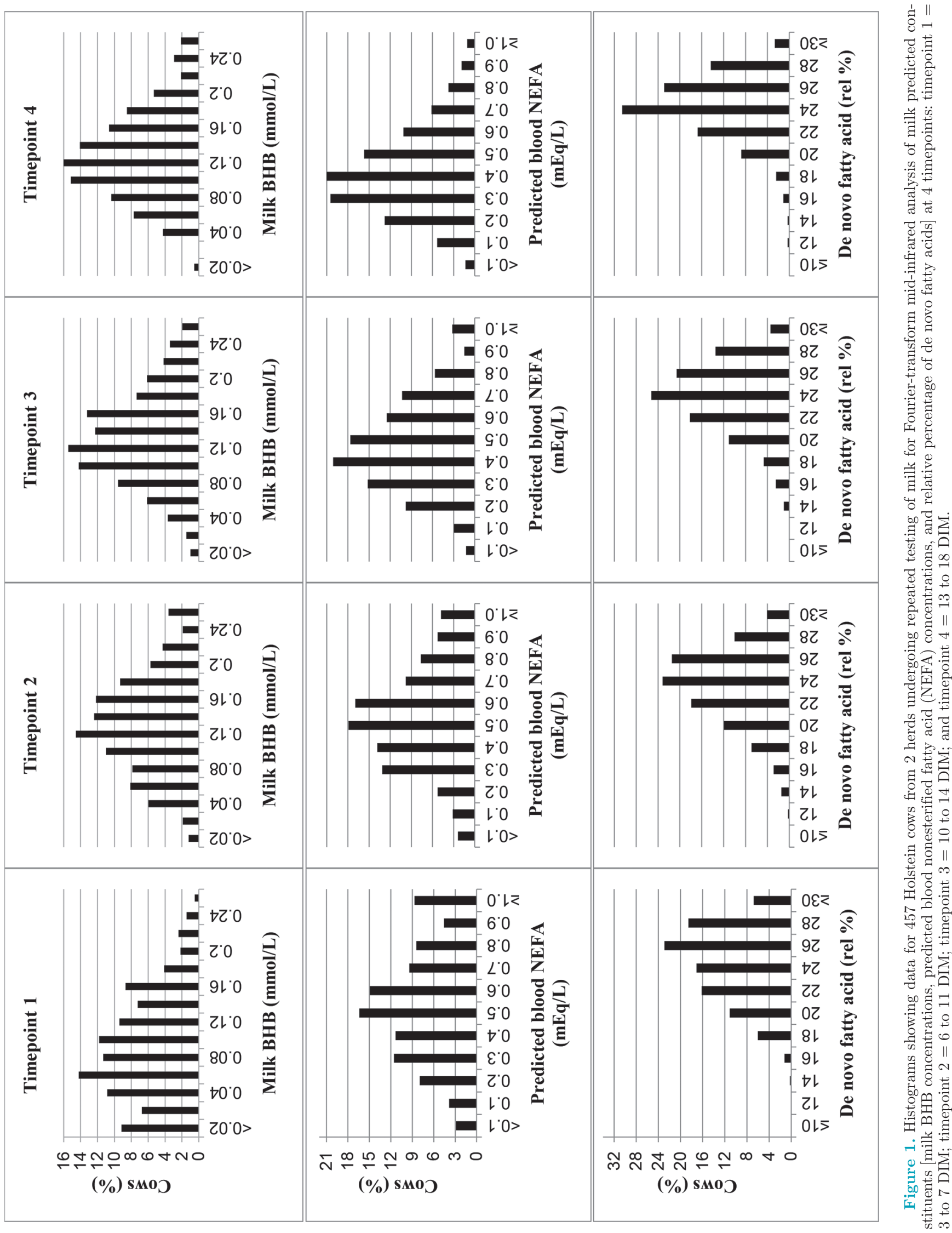



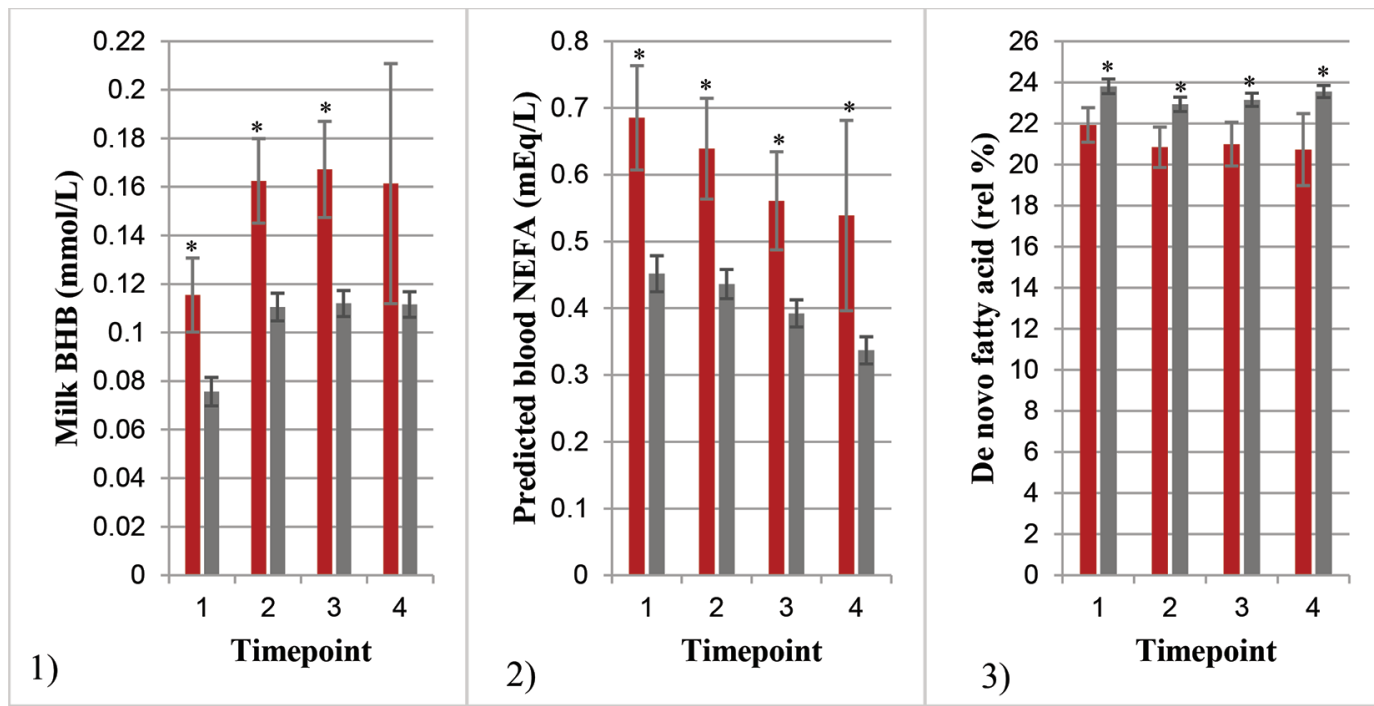

Figure 2. T-test analyses of mean concentration of Fourier-transform mid-infrared analysis of milk predicted constituents: (1) milk BHB concentrations, (2) predicted blood nonesterified fatty acid (NEFA) concentrations, and (3) relative (rel) percentage of de novo fatty acids. Test population was 457 Holstein cows from 2 herds, having a disease or removal event (red bars) or no disease or removal event (gray bars) during each sampling timepoint: timepoint 1 (3 to 7 DIM), timepoint 2 (6 to 11 DIM), timepoint 3 (10 to 14 DIM), or timepoint 4 (13 to 18 DIM). Disease or removal events were defined as any of the following occurring on or following the day of sampling and within the first 30 DIM: cow was sold, died, or was diagnosed with metritis, displaced abomasum, or blood BHB concentration $>1.2$ mmol/L (between 3 and 18 DIM). Error bars represent $95 \%$ confidence intervals. $P$-value reported for Bonferroni corrected $t$-statistic: $* P<0.004$; all others $P=0.2$.

Table 2. Association of Fourier-transform mid-infrared analysis of predicted milk BHB concentrations, predicted blood nonesterified fatty acid (NEFA) concentrations, and relative percentage of de novo fatty acids (FA) in 457 Holstein cows from 2 herds, having a disease or removal event, ${ }^{1}$ tested at 4 timepoints between 3 to 18 DIM

\begin{tabular}{|c|c|c|c|c|c|c|c|c|c|}
\hline Predicted constituent & Timepoint $^{2}$ & $P$-value ${ }^{3}$ & $\mathrm{AUC}^{4}$ & $\begin{array}{l}\text { Cut } \\
\text { point }\end{array}$ & $\mathrm{Se}^{5}$ & $\mathrm{Sp}^{6}$ & $\begin{array}{c}\% \text { of cows } \\
\text { above }^{7} \text { or below } \\
\text { cut point }\end{array}$ & $\mathrm{RR}^{9}$ & $95 \% \mathrm{CI}$ \\
\hline \multirow[t]{3}{*}{ Milk BHB (mmol/L) } & $1^{10}$ & 0.002 & 0.67 & $>0.11$ & 55.8 & 73.6 & 31.9 & 2.0 & 1.3 to 3.0 \\
\hline & $3^{12}$ & $<0.001$ & 0.76 & $>0.14$ & 74.4 & 70.9 & 34.0 & 5.2 & 2.3 to 11.5 \\
\hline & $4^{12}$ & $<0.001$ & 0.70 & $>0.16$ & 61.5 & 85.1 & 16.9 & 9.1 & 2.6 to 31.7 \\
\hline Blood NEFA (mmol/L) & $1^{11}$ & $<0.001$ & 0.71 & $>0.66$ & 53.2 & 82.2 & 24.4 & 2.7 & 1.8 to 4.2 \\
\hline \multirow[t]{4}{*}{ De novo FA (relative \%) } & $1^{11}$ & $<0.001$ & 0.65 & $\leq 22.7$ & 59.7 & 66.8 & 38.2 & 2.9 & 2.0 to 4.4 \\
\hline & $2^{11}$ & $<0.001$ & 0.65 & $\leq 20.2$ & 44.1 & 80.5 & 23.7 & 3.3 & 2.1 to 5.4 \\
\hline & $3^{11}$ & $<0.001$ & 0.69 & $\leq 21.0$ & 61.5 & 78.2 & 26.0 & 5.8 & 3.0 to 11.3 \\
\hline & $4^{13}$ & 0.002 & 0.77 & $\leq 21.1$ & 61.5 & 83.1 & 18.8 & 7.2 & 2.2 to 24.1 \\
\hline
\end{tabular}

${ }^{1}$ Disease or removal events were defined as any of the following occurring on or following the day of sampling and within the first 30 DIM: cow sold, died, or diagnosed with metritis, displaced abomasum, or blood BHB concentration $\geq 1.2 \mathrm{mmol} / \mathrm{L}$ (between 3 and 18 DIM).

${ }^{2}$ Timepoint $1=3$ to 7 DIM $(\mathrm{n}=414) ; 2=6$ to 11 DIM $(\mathrm{n}=401) ; 3=10$ to 14 DIM $(\mathrm{n}=365) ; 4=13$ to 18 DIM (n=314).

${ }^{3} P$-value reported for coefficient estimate for entire variable.

${ }^{4}$ Area under the curve.

${ }^{5}$ Sensitivity.

${ }^{6}$ Specificity.

${ }^{7}$ For milk BHB and predicted blood NEFA.

${ }^{8}$ For de novo FA.

${ }^{9}$ Relative risk.

${ }^{10}$ Other variables that remained in the model were herd $(P<0.001)$ and parity $(P<0.05)$.

${ }^{11}$ Other variable that remained in the model was herd $(P<0.001)$.

${ }^{12}$ Other variable that remained in the model was herd $(P>0.1)$.

${ }^{13}$ Other variable that remained in the model was herd $(P<0.01)$. 
to 18 DIM. This window might have been too narrow to fully elucidate when the peak in milk BHB occurs. If milk BHB does peak after blood BHB, screening for HYK using milk would miss identifying high-risk ani- mals. The low sensitivities at $\mathrm{T} 1$ and $\mathrm{T} 2$, which coincide with the peak prevalence of HYK, support this theory. Additional studies lengthening the screening window might be able to explain this further.
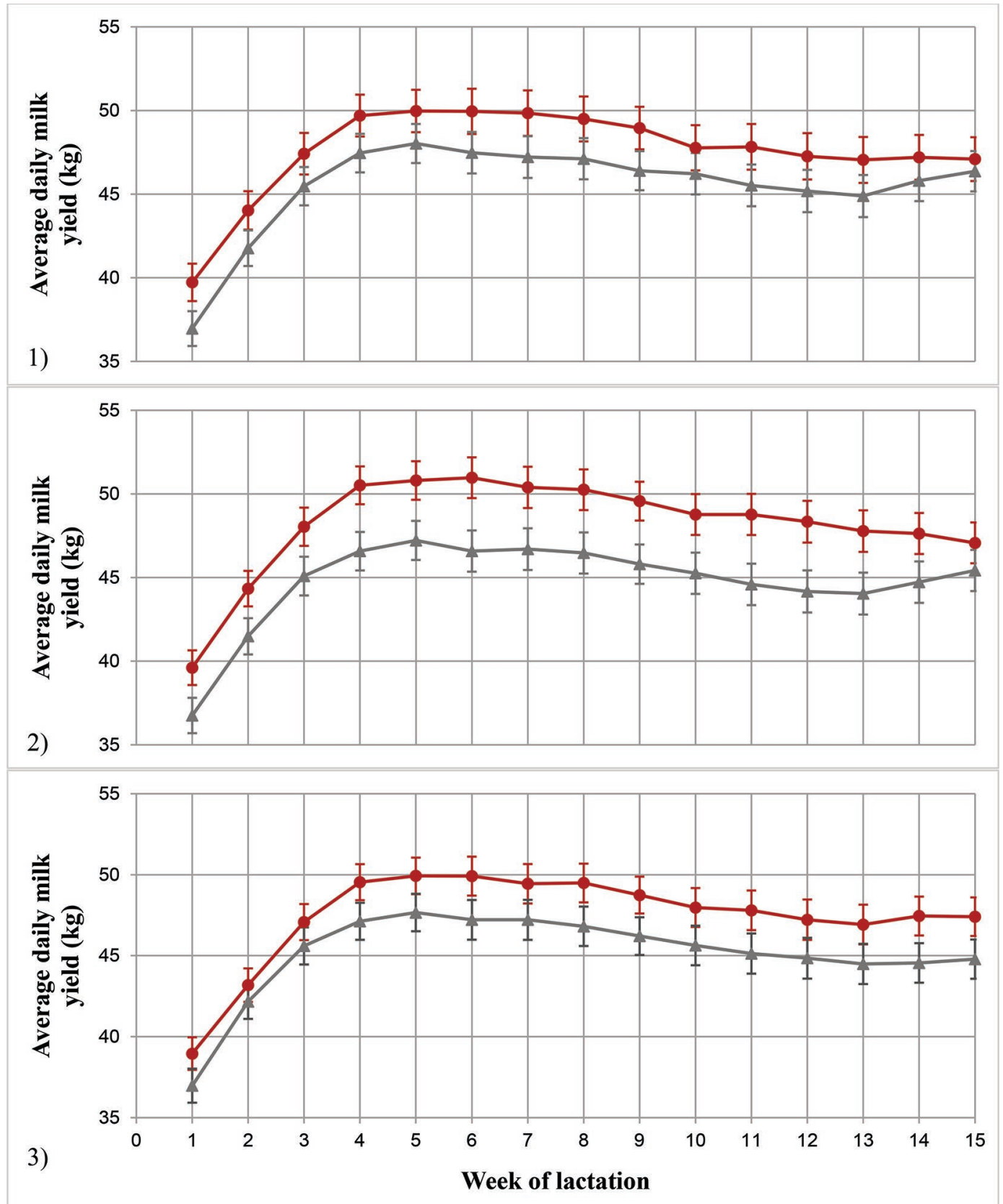

Figure 3. Average daily milk yield during the first 15 wk of lactation for Fourier-transform mid-infrared analysis of milk predicted constituents: (1) milk BHB concentrations, (2) predicted blood nonesterified fatty acid (NEFA) concentrations, and (3) relative percentage of de novo fatty acids (FA), for 457 Holstein cows from 2 herds. Cows that were above the cut point for milk BHB and predicted blood NEFA or below the cut point for de novo FA at any time during the first 18 DIM are denoted by a red line with circles. Cows that were below the cut point for milk BHB and predicted blood NEFA or above the cut point for de novo FA at any time during the first 18 DIM are denoted by a gray line with triangles. The interaction of milk predicted constituent and week of lactation was important for predicted blood NEFA $(P<0.001)$ and demonstrated a tendency for milk BHB $(P=0.06)$ and de novo FA $(P=0.07)$. Additional variables retained in all models included parity (all $P<0.01)$ and locomotion score (all $P<0.005)$. The interaction of farm and week of lactation was retained in the milk BHB model $(P<0.001)$, and farm was retained in the predicted blood NEFA model $(P=0.005)$. Error bars represent $95 \%$ confidence intervals. 
As cut points for milk predicted blood NEFA have not been established, it is interesting to note that optimized cut points were 0.66 and $0.63 \mathrm{mmol} / \mathrm{L}$ for $\mathrm{T} 1$ and $\mathrm{T} 2$, respectively, which is very similar to the cut point that has been established in blood for prediction of clinical disease during a similar time period (0.6 mmol/L; Ospina et al., 2010). By T3 and T4, the cut point dropped to $0.45 \mathrm{mmol} / \mathrm{L}$ and $0.47 \mathrm{mmol} / \mathrm{L}$, respectively. This decrease in milk predicted blood NEFA, which can also be seen in Figures 1 and 2, appears to occur after 10 DIM, mirroring that seen in blood (McCarthy et al., 2015). This suggests that, unlike milk BHB, predicted blood NEFA acts more similarly to its blood counterpart at identifying high-risk animals.

Although we established cut points for de novo FA relative percentages using FTIR, other groups have looked at the association of HYK with FA as determined using gas-liquid chromatography (Jorjong et al., 2015; Mann et al., 2016). Only the study by Mann et al. (2016) demonstrated associations with short-chain FA, which make up de novo FA; however, cut points for these associations cannot be compared, as they were examined on an individual FA basis. Cut points for de novo FA were the most similar over all 4 timepoints, compared with the other 2 milk predicted constituents (Figures 1 and 2). In contrast to our data, previous studies demonstrating changes in milk FA over time show an increase in de novo FA beginning at $1 \mathrm{wk}$ in lactation, which starts to level off around $4 \mathrm{wk}$ in lactation (D. M. Barbano, unpublished data from Lynch et al., 1992). As our data concentrated around the first 2 wk of lactation, we may not have followed out long enough to fully appreciate this increase. Similar to milk BHB, additional studies following de novo FA further into lactation might clarify this.

All predicted constituents (milk BHB, predicted blood NEFA, and de novo FA) were associated with an increased risk of disease or removal during all timepoints sampled during the first 30 DIM. This is not surprising, as all predicted constituents are indicators of early-lactation energy deficit. It is well established in the literature that cows undergoing excessive energy deficit, established by increased blood energy metabolites, are at an increased risk of negative health and production outcomes (Duffield et al., 2009; Ospina et al., 2010; McArt et al., 2012a). Our study, therefore, demonstrates that milk predicted constituents are also indicative of excessive energy deficit and associated with this increased risk of disease or removal.

In general, the relative risk of disease or removal increased as DIM increased. A possible explanation for this is cows that experienced disease or removal after the screening window of 18 DIM. These cows could potentially contribute altered predicted constituents for more than one timepoint, suggesting that the longer they had altered predicted constituents, the greater their risk of eventual disease diagnosis or removal. It is important to note that this should be interpreted with caution, because fewer cows contributed to these later timepoints, as can be observed by the increased variability around each relative risk value. This also highlights another limitation of our study, which was the low incidence of disease or removal compared with other published data (McArt et al., 2012a; Ribeiro et al., 2013). The percentage of HYK cows, however, was similar to prevalence data from similar studies on milk BHB using milk collected during standard DHI sampling (Chandler et al., 2018; Pralle et al., 2018; Renaud et al., 2019) although lower than others with larger herd populations (Tatone et al., 2017).

Interestingly, associations of our measured milk constituents with milk yield during the first $15 \mathrm{wk}$ of lactation were in the opposite direction of those relating to disease or removal, in that cows above the determined cut point for milk BHB and predicted blood NEFA, or below the cut point for de novo FA, showed substantially increased milk production. Previous research looking at HYK demonstrated a decrease in milk production during early lactation for cows with elevated postpartum blood BHB concentrations (Duffield et al., 2009; Chapinal et al., 2012; McArt et al., 2012a). However, Duffield et al. (2009) noted that timing of HYK diagnosis mattered, as cows diagnosed with HYK during the second week of lactation showed increased milk yield during the second and third milk tests following calving. McArt et al. (2012a) also demonstrated the effects of timing at first diagnosis, where cows diagnosed between 3 and 7 DIM produced less than those diagnosed 8 DIM or later. These findings suggest that timing of diagnosis might also be important in milk predicted constituents when identifying associations with milk yield. Furthermore, some evidence suggests that cows that experience excessive energy deficit are likely higher milk producers further into lactation (Duffield et al., 2009; Chapinal et al., 2012).

Another explanation for this direction of association is our choice of cut points. For the analysis of milk production, cut points for each milk constituent were calculated using the average of those determined via disease or removal events at T1-4. Cut points for milk production may be different than cut points for disease or removal. A study by Tatone et al. (2017) calculated milk BHB cut points from first test-day milk production data in a stepwise manner, determining that the lowest cut point with a negative estimate for milk production was $0.15 \mathrm{mmol} / \mathrm{L}$. This value was quite similar to our cut point of $0.14 \mathrm{mmol} / \mathrm{L}$. However, because those samples were from monthly DHI testing, the average 
DIM at milk sample collection was 17 DIM, which is almost the end of our sampling range. As Renaud et al. (2019) demonstrated that cut points for cows with greater DIM required a reduced cut point as compared with those with lower DIM, it might be that our cut point is too low to see a difference in production over time.

\section{CONCLUSIONS}

This study demonstrates that milk predicted constituents (milk BHB, predicted blood NEFA, and de novo FA) sampled at any point during the first 18 DIM are associated with an increased risk of disease or removal during the first 30 DIM. Although we found an effect of milk predicted constituents by time on average daily milk production during the first 15 wk of lactation, the association was not what was expected. Using a cut point calculated from ROC analysis of disease or removal, cows above the cut point for predicted milk BHB and predicted blood NEFA and below the cut point for de novo FA relative percentages had increased milk production during the examined period, compared with those that did not cross the cut point. This discrepancy between previous research on blood BHB and NEFA suggests that further investigation of the association between milk predicted constituents and milk production is necessary. However, our results suggest that FTIR-predicted milk BHB, blood NEFA, and milk de novo FA relative percentages are promising indicators of subsequent disease or removal in early lactation.

\section{ACKNOWLEDGMENTS}

This study was funded by the USDA National Institute of Food and Agriculture Hatch project no. 1007331. The authors thank Nova Biomedical (Waltham, MA) for providing BHB meters and strips, Charlene Ryan, Rafael Neves, Stephanie Tarlowe, Jamie Horstmann, and Mariah Goodwin (Cornell University, Ithaca, NY) for their assistance with sample collection, and Chassidy Coon and the rest of the Barbano Laboratory (Cornell University, Ithaca, NY) for milk analysis. We also thank the owners of the collaborating dairies for allowing us access to their cows and facilities on which to conduct this research.

\section{REFERENCES}

AOAC International. 2000. Official Methods of Analysis. 17th ed. Association of Official Analytical Chemists, Arlington, VA.

Bach, K. D., W. Heuwieser, and J. A. A. McArt. 2016. Technical note: Comparison of 4 electronic handheld meters for diagnosing hyperketonemia in dairy cows. J. Dairy Sci. 99:9136-9142. https://doi .org/10.3168/jds.2016-11077.
Baird, G. D. 1982. Primary ketosis in the high-producing dairy cow: Clinical and subclinical disorders, treatment, prevention, and outlook. J. Dairy Sci. 65:1-10. https://doi.org/10.3168/jds.s0022 $-0302(82) 82146-2$.

Bauman, D. E., and W. B. Currie. 1980. Partitioning of nutrients during pregnancy and lactation: A review of mechanisms involving homeostasis and homeorhesis. J. Dairy Sci. 63:1514-1529. https:// doi.org/10.3168/jds.s0022-0302(80)83111-0.

Chandler, T. L., R. S. Pralle, J. R. R. Dórea, S. E. Poock, G. R. Oetzel, R. H. Fourdraine, and H. M. White. 2018. Predicting hyperketonemia by logistic and linear regression using test-day milk and performance variables in early-lactation Holstein and Jersey cows. J. Dairy Sci. 101:2476-2491. https://doi.org/10.3168/jds .2017-13209.

Chapinal, N., M. Carson, T. F. Duffield, M. Capel, S. Godden, M. Overton, J. E. P. Santos, and S. J. LeBlanc. 2011. The association of serum metabolites with clinical disease during the transition period. J. Dairy Sci. 94:4897-4903. https://doi.org/10.3168/jds $.2010-4075$.

Chapinal, N., S. J. LeBlanc, M. E. Carson, K. E. Leslie, S. Godden, M. Capel, J. E. P. Santos, M. W. Overton, and T. F. Duffield. 2012. Herd-level association of serum metabolites in the transition period with disease, milk production, and early lactation reproductive performance. J. Dairy Sci. 95:5676-5682. https://doi.org/10 $.3168 /$ jds.2011-5132.

de Roos, A. P. W., H. J. C. M. van den Bijgaart, J. Hørlyk, and G. de Jong. 2007. Screening for subclinical ketosis in dairy cattle by Fourier transform infrared spectrometry. J. Dairy Sci. 90:1761-1766. https://doi.org/10.3168/jds.2006-203.

Denis-Robichaud, J., J. Dubuc, D. Lefebvre, and L. DesCôteaux. 2014. Accuracy of milk ketone bodies from flow-injection analysis for the diagnosis of hyperketonemia in dairy cows. J. Dairy Sci. 97:33643370. https://doi.org/10.3168/jds.2013-6744.

Duffield, T. F., D. F. Kelton, K. E. Leslie, K. D. Lissemore, and J. H. Lumsden. 1997. Use of test day milk fat and milk protein to detect subclinical ketosis in dairy cattle in Ontario. Can. Vet. J. $38: 713-718$.

Duffield, T. F., K. D. Lissemore, B. W. McBride, and K. E. Leslie. 2009. Impact of hyperketonemia in early lactation dairy cows on health and production. J. Dairy Sci. 92:571-580. https://doi.org/ 10.3168/jds.2008-1507.

Duffield, T. F., D. Sandals, K. E. Leslie, K. Lissemore, B. W. McBride, J. H. Lumsden, P. Dick, and R. Bagg. 1998. Efficacy of monensin for the prevention of subclinical ketosis in lactating dairy cows. J. Dairy Sci. 81:2866-2873. https://doi.org/10.3168/jds.S0022 -0302(98)75846-1.

Ferguson, J. D., D. T. Galligan, and N. Thomsen. 1994. Principal descriptors of body condition score in Holstein cows. J. Dairy Sci. 77:2695-2703. https://doi.org/10.3168/jds.S0022-0302(94)77212 $-\mathrm{X}$.

Fitts, J. E., and D. Laird. 2004. Direct microscopic method for bacteria or somatic cells. Pages 269-280 in Standard Methods for the Examination of Dairy Products. 17th ed. H. M. Wehr and J. F. Frank, ed. American Public Health Association, Washington, DC.

Herdt, T. H. 2000. Ruminant adaptation to negative energy balance: Influences on the etiology of ketosis and fatty liver. Vet. Clin. North Am. Food Anim. Pract. 16:215-230. https://doi.org/10 .1016/S0749-0720(15)30102-X.

Iwersen, M., U. Falkenberg, R. Voigtsberger, D. Forderung, and W. Heuwieser. 2009. Evaluation of an electronic cowside test to detect subclinical ketosis in dairy cows. J. Dairy Sci. 92:2618-2624. https: //doi.org/10.3168/jds.2008-1795.

Iwersen, M., D. Klein-Jöbstl, M. Pichler, L. Roland, B. Fidlschuster, I. Schwendenwein, and M. Drillich. 2013. Comparison of 2 electronic cowside tests to detect subclinical ketosis in dairy cows and the influence of the temperature and type of blood sample on the test results. J. Dairy Sci. 96:7719-7730. https://doi.org/10.3168/ jds.2013-7121.

Jorjong, S., A. T. M. van Knegsel, J. Verwaeren, R. M. Bruckmaier, B. De Baets, B. Kemp, and V. Fievez. 2015. Milk fatty acids as pos- 
sible biomarkers to diagnose hyperketonemia in early lactation. J. Dairy Sci. 98:5211-5221. https://doi.org/10.3168/jds.2014-8728.

Kaylegian, K. E., G. E. Houghton, J. M. Lynch, J. R. Fleming, and D. M. Barbano. 2006. Calibration of infrared milk analyzers: Modified milk versus producer milk. J. Dairy Sci. 89:2817-2832. https://doi .org/10.3168/jds.S0022-0302(06)72555-3.

Kaylegian, K. E., J. M. Lynch, J. R. Fleming, and D. M. Barbano. 2009. Influence of fatty acid chain length and unsaturation on midinfrared milk analysis. J. Dairy Sci. 92:2485-2501. https://doi.org/ 10.3168/jds.2008-1910.

Luke, T. D. W., S. Rochfort, W. J. Wales, V. Bonfatti, L. Marett, and J. E. Pryce. 2019. Metabolic profiling of early-lactation dairy cows using milk mid-infrared spectra. J. Dairy Sci. 102:1747-1760. https://doi.org/10.3168/jds.2018-15103.

Lynch, J. M., D. M. Barbano, D. E. Bauman, G. F. Hartnell, and M. A. Nemeth. 1992. Effect of a prolonged-release formulation of n-methionyl bovine somatotropin (sometribove) on milk fat. J. Dairy Sci. 75:1794-1809. https://doi.org/10.3168/jds.S0022 -0302(92) 77938-7.

Mann, S., D. V. Nydam, A. L. Lock, T. R. Overton, and J. A. A. McArt. 2016. Short communication: Association of milk fatty acids with early lactation hyperketonemia and elevated concentration of nonesterified fatty acids. J. Dairy Sci. 99:5851-5857. https: //doi.org/10.3168/jds.2016-10920.

McArt, J. A. A., D. V. Nydam, and G. R. Oetzel. 2012a. Epidemiology of subclinical ketosis in early lactation dairy cattle. J. Dairy Sci. 95:5056-5066. https://doi.org/10.3168/jds.2012-5443.

McArt, J. A. A., D. V. Nydam, and G. R. Oetzel. 2012b. A field trial on the effect of propylene glycol on displaced abomasum, removal from herd, and reproduction in fresh cows diagnosed with subclinical ketosis. J. Dairy Sci. 95:2505-2512. https://doi.org/10.3168/ jds.2011-4908.

McCarthy, M. M., S. Mann, D. V. Nydam, T. R. Overton, and J. A. McArt. 2015. Short communication: Concentrations of nonesterified fatty acids and beta-hydroxybutyrate in dairy cows are not well correlated during the transition period. J. Dairy Sci. 98:62846290. https://doi.org/10.3168/jds.2015-9446.

Megahed, A. A., M. W. Hiew, J. R. Townsend, and P. D. Constable. 2017. Characterization of the analytic performance of an electrochemical point-of-care meter for measuring $\beta$-hydroxybutyrate concentration in blood and plasma from periparturient dairy cattle. Vet. Clin. Pathol. 46:314-325. https://doi.org/10.1111/vcp.12493.

Ospina, P. A., D. V. Nydam, and T. J. DiCiccio. 2012. Technical note: The risk ratio, an alternative to the odds ratio for estimating the association between multiple risk factors and a dichotomous outcome. J. Dairy Sci. 95:2576-2584. https://doi.org/10.3168/jds $.2011-4515$.

Ospina, P. A., D. V. Nydam, T. Stokol, and T. R. Overton. 2010. Evaluation of nonesterified fatty acids and beta-hydroxybutyrate in transition dairy cattle in the northeastern United States: Critical thresholds for prediction of clinical diseases. J. Dairy Sci. 93:546-554. https://doi.org/10.3168/jds.2009-2277.

Palmquist, D. L., C. L. Davis, R. E. Brown, and D. S. Sachan. 1969. Availability and metabolism of various substrates in ruminants. V. Entry rate into the body and incorporation into milk fat of $\mathrm{D}(-)$ ß-hydroxybutyrate. J. Dairy Sci. 52:633-638. https://doi.org/10 .3168/jds.S0022-0302(69)86620-8.

Pape, A., H. M. Dann, D. M. Barbano, and R. J. Grant. 2018. Detection of health problems by changes in milk estimated blood nonesterified fatty acids (NEFA) and milk fat, protein, and fatty acids. J. Dairy Sci. 101:39 (Suppl. 2).
Pralle, R. S., K. W. Weigel, and H. M. White. 2018. Predicting blood $\beta$-hydroxybutyrate using milk Fourier transform infrared spectrum, milk composition, and producer-reported variables with multiple linear regression, partial least squares regression, and artificial neural network. J. Dairy Sci. 101:4378-4387. https://doi .org/10.3168/jds.2017-14076.

Renaud, D. L., D. F. Kelton, and T. F. Duffield. 2019. Short communication: Validation of a test-day milk test for $\beta$-hydroxybutyrate for identifying cows with hyperketonemia. J. Dairy Sci. 102:15891593. https://doi.org/10.3168/jds.2018-14778.

Ribeiro, E. S., F. S. Lima, L. F. Greco, R. S. Bisinotto, A. P. A. Monteiro, M. Favoreto, H. Ayres, R. S. Marsola, N. Martinez, W. W. Thatcher, and J. E. P. Santos. 2013. Prevalence of periparturient diseases and effects on fertility of seasonally calving grazing dairy cows supplemented with concentrates. J. Dairy Sci. 96:5682-5697. https://doi.org/10.3168/jds.2012-6335.

Santschi, D. E., R. Lacroix, J. Durocher, M. Duplessis, R. K. Moore, and D. M. Lefebvre. 2016. Prevalence of elevated milk $\beta$-hydroxybutyrate concentrations in Holstein cows measured by Fourier-transform infrared analysis in Dairy Herd Improvement milk samples and association with milk yield and components. J. Dairy Sci. 99:9263-9270. https://doi.org/10.3168/jds.2016-11128.

Sprecher, D. J., D. E. Hostetler, and J. B. Kaneene. 1997. A lameness scoring system that uses posture and gait to predict dairy cattle reproductive performance. Theriogenology 47:1179-1187. https:// doi.org/10.1016/S0093-691X(97)00098-8.

Swets, J. A. 1988. Measuring the accuracy of diagnostic systems. Science 240:1285-1293. https://doi.org/10.1126/science.3287615.

Tatone, E. H., T. F. Duffield, S. J. LeBlanc, T. J. DeVries, and J. L. Gordon. 2017. Investigating the within-herd prevalence and risk factors for ketosis in dairy cattle in Ontario as diagnosed by the test-day concentration of $\beta$-hydroxybutyrate in milk. J. Dairy Sci. 100:1308-1318. https://doi.org/10.3168/jds.2016-11453.

van der Drift, S. G. A., R. Jorritsma, J. T. Schonewille, H. M. Knijn, and J. A. Stegeman. 2012. Routine detection of hyperketonemia in dairy cows using Fourier transform infrared spectroscopy analysis of $\beta$-hydroxybutyrate and acetone in milk in combination with test-day information. J. Dairy Sci. 95:4886-4898. https://doi.org/ $10.3168 /$ jds.2011-4417.

van Knegsel, A. T. M., H. van den Brand, J. Dijkstra, S. Tamminga, and B. Kemp. 2005. Effect of dietary energy source on energy balance, production, metabolic disorders and reproduction in lactating dairy cattle. Reprod. Nutr. Dev. 45:665-688. https://doi.org/ 10.1051/rnd:2005059.

Wojciechowski, K. L., and D. M. Barbano. 2016. Prediction of fatty acid chain length and unsaturation of milk fat by mid-infrared milk analysis. J. Dairy Sci. 99:8561-8570. https://doi.org/10 .3168/jds.2016-11248.

Wojciechowski, K. L., C. Melilli, and D. M. Barbano. 2016. A proficiency test system to improve performance of milk analysis methods and produce reference values for component calibration samples for infrared milk analysis. J. Dairy Sci. 99:6808-6827. https:/ /doi.org/10.3168/jds.2016-10936.

Woolpert, M. E., H. M. Dann, K. W. Cotanch, C. Melilli, L. E. Chase, R. J. Grant, and D. M. Barbano. 2016. Management, nutrition, and lactation performance are related to bulk tank milk de novo fatty acid concentration on northeastern US dairy farms. J. Dairy Sci. 99:8486-8497. https://doi.org/10.3168/jds.2016-10998. 